\title{
小麦产量与品质对灌浆不同阶段高温胁迫的响应
}

\author{
李永庚 ${ }^{1,2}$ 于振文 ${ }^{2 *}$ 张秀杰 ${ }^{1}$ 高雷明 1
}

(1 中国科学院植物研究所植被数量生态学重点实验室, 北京 100093)

（2 山东农业大学农学院, 农业部小麦栽培生理与遗传改良重点开放实验室, 泰安 271018)

摘 要 利用人工环境控制室对盆栽冬小麦(品种: ‘济南 17’ 和 ‘鲁麦 21’)( Triticum aestivum cv. 'Ji' nan17’ and “Lumai21' ) 分别在子粒灌浆前期、中期和后期进行了 $25{ }^{\circ} \mathrm{C} / 35{ }^{\circ} \mathrm{C}$ (夜/昼) 的高温胁迫处理, 以生长在 $20{ }^{\circ} \mathrm{C} / 30{ }^{\circ} \mathrm{C}$ (夜/昼)环境中的小麦为对照, 研究了灌浆期不同阶段高温胁迫对小麦产量和品质的影响。结果发现: 1)子粒蛋白 质积累速率在高温处理期间显著提高 $(p<0.05)$, 但高值持续期缩短, 并最终造成植株氮素积累量减少, 氮素收获 指数降低 $(p<0.05)$ 。2) 小麦蛋白质的组成和品质对不同灌浆阶段的响应存在显著差异, 前期高温胁迫导致麦谷 蛋白/醇溶蛋白的比值以及麦谷蛋白大聚合体 (GMP) 含量增加, 标志蛋白质和淀粉品质的湿面筋含量升高、沉降值 增加、膨胀势和高峰粘度等指标也显著提高; 灌浆中期高温却导致上述指标降低; 灌浆后期高温在造成粒重减小、 产量降低和淀粉品质下降的同时, 却有利于蛋白质含量的提高。3) 小麦淀粉积累的形成与蛋白质品质的形成是两 个既相互联系又相互独立的过程, 高温条件下子粒蛋白质含量的升高是淀粉积累量减少造成的。

关键词 小麦 高温 品质 蛋白质 淀粉

\section{RESPONSE OF YIELD AND QUALITY OF WHEAT TO HEAT STRESS AT DIFFERENT GRAIN FILLING STAGES}

\author{
LI Yong-Geng $^{1,2}$ YU Zhen-Wen ${ }^{2 *} \quad$ ZHANG Xiu-Jie $^{1}$ and GAO Lei-Ming ${ }^{1}$ \\ (1 Laboratory of Quantitative Vegetation Ecology, Institute of Botany, Chinese Academy of Sciences, Beijing 100093, China) \\ (2 Wheat Planting Physiology \& Heredity Improve Key Opening Laboratory of Agricultural Ministry, Agronomy College, \\ Shandong Agricultural University, Taian, Shandong 271018, China)
}

\begin{abstract}
Changes in the yields and quality and the physiological response of winter wheat ( Triticum aestivum cv. 'Ji'nan17' and 'Lumai21') grown under heat stress during different filling stages were studied. Winter wheat growing in flowerpots was transferred to temperature-controlled open top chambers (OTC) after anthesis. Heat stress treatments of $25{ }^{\circ} \mathrm{C} / 35^{\circ} \mathrm{C}$ (night/day) were applied at early filling stage $(1-10$ days after anthesis), middle filling stage ( $11-20$ days after anthesis), and late filling stage ( $21-30$ days after anthesis). The controls were grown at temperatures of $20{ }^{\circ} \mathrm{C} / 30{ }^{\circ} \mathrm{C}$ (night/day). Protein accumulation rate, nitrogen accumulation and distribution, kernel weight and yield, test weight, protein composition, protein content, wet gluten content, glutenin macropolymer (GMP) content, and starch and protein quality traits were measured. The results showed that protein accumulation rate in wheat kernels grown in the $25{ }^{\circ} \mathrm{C} / 35{ }^{\circ} \mathrm{C}$ ( night/day) chambers were higher than those in the control chambers $(p<0.05)$; however, nitrogen accumulation was reduced and the nitrogen harvest index $(\mathrm{NHI})$ declined under heat stress $(p<0.05)$. There were differences in starch and protein quality responses to heat stress during the different filling stages. Protein and starch quality traits improved at the early filling stage but declined at the middle and late filling stages under heat stress; however, the protein content increased at late filling stage under heat stress. Protein content increased but kernel weight decreased under higher temperatures, which suggested that the starch accumulation rate decreased more sharply than protein accumulation rates under higher temperature. The two varieties, 'Ji' nan17' and 'Lumai21', showed similar responses to heat stress at the different filling stages.
\end{abstract}

Key words Winter wheat, Heat stress, Protein, Starch, Quality 
1989; Smith \& Gooding, 1996)、温度 (Randall \& Moss, 1990, Blumenthal et al., 1993; Keeling et al., 1993)、 光照 (Wardlaw, 1970; Spiertz, 1974) 以及综合环境因子 （Graybosch \& Peterson, 1995; 朱金宝等,1995)对小麦 品质的影响受到广泛关注。

研究发现, 小麦子粒形成阶段的温度条件不仅 影响小麦的光合物质生产量, 而且对小麦子粒灌浆 特性、产量和品质有显著的影响 (Blumenthal et al., 1991; 廖建雄和王根轩, 2000)。李永庚等(2003)在 总结前人的工作后认为, 温度超过 $30{ }^{\circ} \mathrm{C}$ 时对提高小 麦品质不利。但是, 高温胁迫在小麦灌浆期内有其 时空分布特点, 不同灌浆阶段的高温胁迫对小麦产 量和品质的影响及其相关的生理基础可能有所不 同,但目前并不清楚。

高温胁迫对我国小麦的危害主要表现为干热 风, 可使灌浆期缩短、粒重降低。全球气候变暖 （IPCC, 1992), 小麦受到干热风的危害将明显加重, 产量和品质将受到不利的影响。本研究利用人工环 境控制室在小麦子粒灌浆的前期、中期和后期进行 不同的温度处理, 通过测定不同温度环境下蛋白质 积累速率、氮素的积累与分配、蛋白质的组成等生理 特性, 揭示不同灌浆阶段高温胁迫对产量和品质的 影响及其生理基础。

\section{1 材料和方法}

\section{1 种植条件}

试验于 $2002 \sim 2003$ 年在中国科学院植物研究 所进行。供试品种为 “济南 17 ' ('Ji'nan17') 和 '鲁 麦 21'( 'Lumai21')。所选用的栽培方式为盆栽, 盆 的内径为 $30 \mathrm{~cm}$, 盆内深度为 $35 \mathrm{~cm}$, 实际装土深度为 $30 \mathrm{~cm}$; 所装土壤为 $20 \mathrm{~kg}$ 壤土, 其有机质、速效氮、速 效磷、速效钾含量分别为 $1.05 \% 、 98.13 \mathrm{mg} \cdot \mathrm{kg}^{-1}$ 、 $12.18 \mathrm{mg} \bullet \mathrm{kg}^{-1} 、 75.97 \mathrm{mg} \bullet \mathrm{kg}^{-1}$ 。播种前按每盆有机 肥 $750 \mathrm{~g}$ 、纯氮 $1.05 \mathrm{~g} 、 \mathrm{P}_{2} \mathrm{O}_{5} 1.35 \mathrm{~g} 、 \mathrm{~K}_{2} \mathrm{O} 2.25 \mathrm{~g}$ 施入基 肥, 每盆种 8 株, 并在小麦拔节期每盆追施纯氮 $1.05 \mathrm{~g}$ 。

\section{2 试验设计}

小麦开花后,移入温度条件不同的人工环境控 制室内。人工环境控制室设计方法为: 利用开顶式 同化箱 (Open top chamber, OTC) 并辅以四套 $500 \mathrm{~W}$ 热 风机进行人工温度控制, 达到 $20{ }^{\circ} \mathrm{C} / 30{ }^{\circ} \mathrm{C}$ (夜/昼) 和 $25{ }^{\circ} \mathrm{C} / 35{ }^{\circ} \mathrm{C}$ (夜/昼) 的 OTC 内小麦冠层温度, 温 度控制的偏差在 $\pm 0.5{ }^{\circ} \mathrm{C}$ 以内。 OTC 的规格为长 $\times$ 宽 $\times$ 高 $=1.5 \mathrm{~m} \times 2.0 \mathrm{~m} \times 1.6 \mathrm{~m}$, 可容纳 24 盆 小麦。共设 $\mathrm{T} 0 、 \mathrm{~T} 1 、 \mathrm{~T} 2$ 和 $\mathrm{T} 34$ 个处理(表 1), 每个处 理重复 3 次。

表 1 小麦灌浆期不同阶段各个处理的温度条件

Table 1 Temperature condition of each treatment at different grain filling stage

\begin{tabular}{|c|c|c|c|c|}
\hline \multirow{2}{*}{$\begin{array}{l}\text { 代号 } \\
\text { Codes }\end{array}$} & \multirow{2}{*}{$\begin{array}{c}\text { 处理名称 } \\
\text { Treatment names }\end{array}$} & \multicolumn{3}{|c|}{ 夜/昼温度 Night/Day temperature $\left({ }^{\circ} \mathrm{C}\right)$} \\
\hline & & $\begin{array}{c}\text { 开花后 1 10 天 } \\
1 \text { - 10DAA }\end{array}$ & $\begin{array}{c}\text { 开花后 } 11 \sim 20 \text { 天 } \\
11 \text { - 20DAA }\end{array}$ & $\begin{array}{c}\text { 开花后 } 21 \sim 30 \text { 天 } \\
21 \text { - 30DAA }\end{array}$ \\
\hline T0 & $\begin{array}{l}\text { 对照 } \\
\text { Control }\end{array}$ & $20 / 30$ & $20 / 30$ & $20 / 30$ \\
\hline $\mathrm{T} 1$ & $\begin{array}{l}\text { 前期高温胁迫 } \\
\text { Early heat stress }\end{array}$ & $25 / 35$ & $20 / 30$ & $20 / 30$ \\
\hline $\mathrm{T} 2$ & $\begin{array}{l}\text { 中期高温胁迫 } \\
\text { Middle heat stress }\end{array}$ & $20 / 30$ & $25 / 35$ & $20 / 30$ \\
\hline $\mathrm{T} 3$ & $\begin{array}{l}\text { 后期高温斜胁迫 } \\
\text { Later heat stress }\end{array}$ & $20 / 30$ & $20 / 30$ & $25 / 35$ \\
\hline
\end{tabular}

DAA: Days after anthesis

\section{3 取样方法}

在小麦开花期标记同一日开花的麦穗。分别在 小麦开花后 $0 、 5 、 10 、 15 、 20 、 25 、 30 、 35$ 天取样, 每重复 取 3 个单茎, 分为子粒和营养器官, $70{ }^{\circ} \mathrm{C}$ 烘干。

\section{4 测定方法}

含氮量的测定: 半微量凯氏定氮法, 采用瑞士 产 KJ-419 型半自动定氮系统测定含氮量, 子粒含氮
量乘以 5.7 后为子粒蛋白质含量。

蛋白质各组分含量：根据各种蛋白质组分在不 同溶剂中的溶解特性, 分步提取后取上清液, 用双缩 脲试剂显色后在 $540 \mathrm{~nm}$ 比色, 以牛血清蛋白做标准 曲线。

麦谷蛋白大聚合体 (GMP) 含量: 参照孙辉等 （1998）的方法。 $50 \mathrm{mg}$ 小麦粉中加入 $1 \mathrm{ml} 1.5 \%$ 的 
SDS 提取液, 震荡摇匀, 室温下 $15500 \times \mathrm{g}$ 离心 15 $\min$, 弃上清液, 利用双缩嫝法测定残余物的含氮量 作为 GMP 的含量。

RVA 参数: 用澳大利亚产 RVA Super3 型快速 粘度仪测定。

膨胀势: 采用 McCormick \& Panozzo (1994)的方 法测定。

SDS-沉降值: 采用 GB/T15685-1995 的方法。

\section{5 数据处理与分析}

利用 SPSS 10.0 汇总分析数据。

\section{2 结果与分析}

\section{1 蛋白质积累速率}

高温胁迫后，小麦子粒蛋白质积累速率明显加 快; 但高温胁迫结束后, 蛋白质积累速率便开始下降 并且导致灌浆速率的高值持续期缩短。其中, 灌浆 前期的高温影响最为明显, 蛋白质积累的峰值出现 时间较对照处理提前了大约 $5 \mathrm{~d}$ (图 1A)。

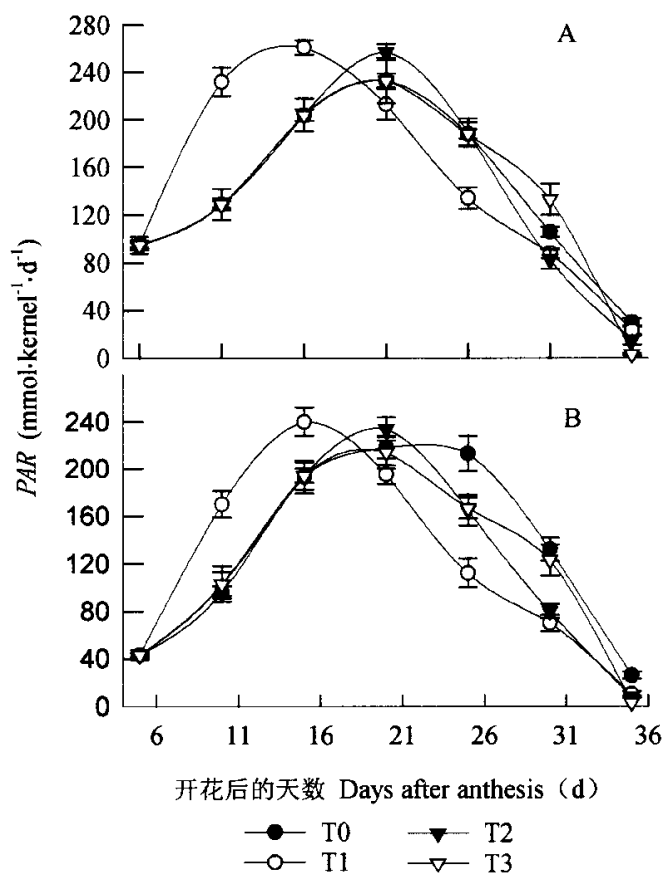

图 1 小麦子粒灌浆前期、中期和后期高温胁迫对 “济南 17’(A)和 “鲁麦 21’ (B)子粒蛋白质积累速率 (PAR) 的影响

Fig. 1 Protein accumulation rate ( $P A R)$ of 'Ji' nan17' (A) and 'Lumai21' (B) under heat stress

$\mathrm{T} 0$ 为对照, $\mathrm{T} 1 、 \mathrm{~T} 2$ 和 $\mathrm{T} 3$ 分别代表仅在子粒灌浆前期、中期和后 期小麦受到了 $25{ }^{\circ} \mathrm{C} / 35^{\circ} \mathrm{C}$ (夜/昼)的高温胁迫 T0 represent the control, T1, T2 and T3 represent the wheat suffered $25{ }^{\circ} \mathrm{C} / 35{ }^{\circ} \mathrm{C}$ ( night/day) heat stress during early, middle and late filling stage, respectively

\section{2 氮素积累与分配}

灌浆前期高温胁迫导致氮素积累量显著增加 $(p<0.05)$, 灌浆后期高温胁迫导致氮素积累量显著 减少 $(p<0.05)$, 而中期高温胁迫导致的变化不明显 $(p>0.05)$ (图 2A)。由于高温条件下子粒氮素积累 量减少和营养器官中氮素残留量增加, 导致了高温 胁迫后氮素收获指数的显著降低, 但不同灌浆阶段 高温胁迫之间的差异并不显著 $(p>0.05$ )(图 2B)。 ‘济南 17 ’ 和 ‘鲁麦 21 ’ 所表现出的趋势相一致。

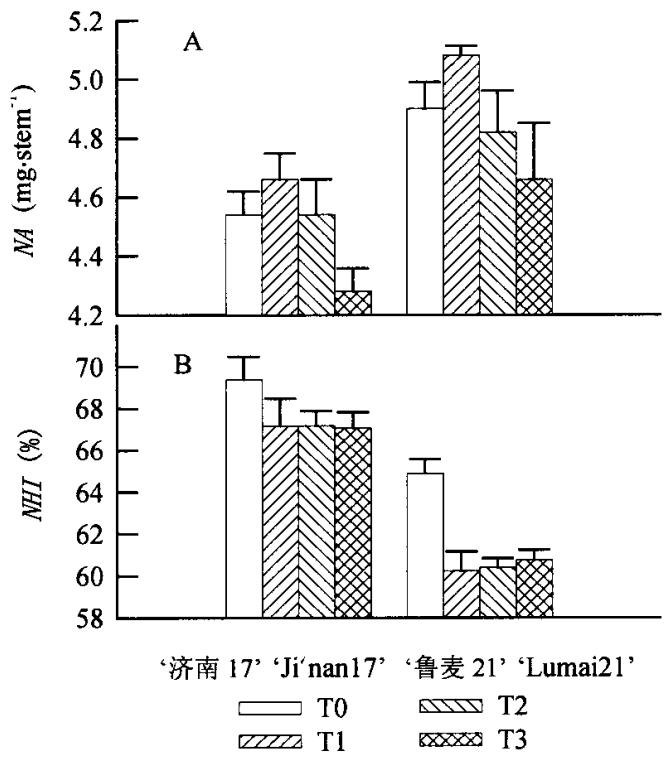

图 2 小麦子粒灌浆前期、中期和后期高温胁迫对 “济南 17’ 和 ‘鲁麦 21’ 的植株氮素积累量 $(N A)(\mathrm{A})$ 和氮素收获指数 $(N H I)(\mathrm{B})$ 的影响

Fig.2 Nitrogen accumulations ( NA) (A) and nitrogen harvest index ( $\mathrm{NHI}$ ）(B) of 'Ji' nan17' and 'Lumai21' under heat stress T0, T1, T2, T3: 同图 1 See Fig. 1

\section{3 子粒蛋白质各组分含量}

小麦面粉中的麦谷蛋白和醇溶蛋白与面筋的粘 一弹特性关系密切, 醇溶蛋白含量较低而麦谷蛋白含 量相对较高, 有利于形成强度较高的面筋, 对于改善 蛋白质品质有重要的意义。灌浆前期受高温胁迫的 小麦的麦谷蛋白含量显著升高 $(p<0.05$ ) (图 3B), 而醇溶蛋白含量未发生显著变化(图 3A), 导致麦谷 蛋白/醇溶蛋白含量的比值升高 (图 3C)。灌浆中、 后期受高温胁迫的小麦麦谷蛋白含量显著降低 (图 3B), 而醇溶蛋白含量显著升高(图 3A), 使麦谷蛋白 与醇溶蛋白含量的比值降低(图 3C)。

\subsection{GMP 含量}

麦谷蛋白大聚合体 (GMP) 是由高分子量的麦谷 蛋白亚基 (HMW-GS) 和低分子量的麦谷蛋白亚基 （LMW-GS）相互交联形成的, 是反映麦谷蛋白分布的 一个重要指标, 对面筋和面团的粘-弹性极为重要, 
与面粉的加工品质关系密切。在灌浆前期受到高温 后的小麦子粒 GMP 含量显著升高 $(p<0.05)$ 。而灌 浆中、后期高温胁迫导致 GMP 含量显著降低 $(p<$ 0.05 ), 不利于小麦品质的改善。“济南 17 ’ 和 ‘鲁 麦 21' 所表现出的趋势一致(图 3D)。

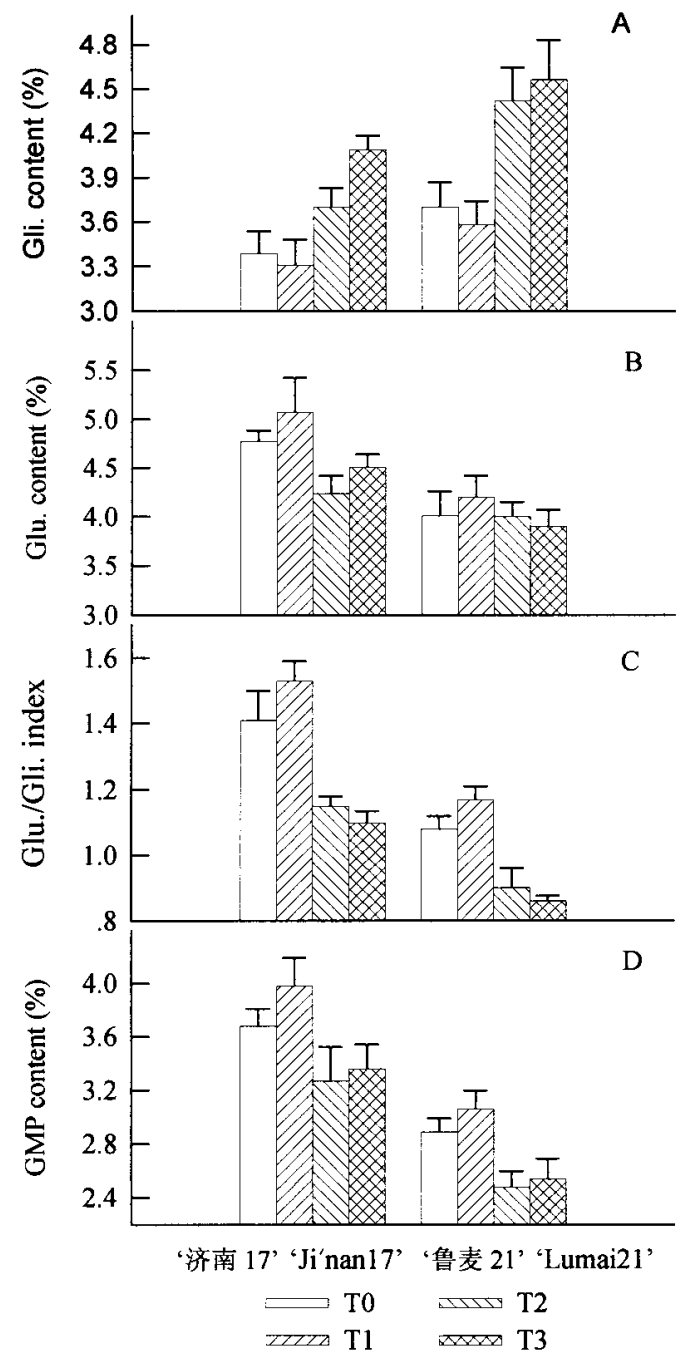

图 3 小麦子粒灌浆前期、中期和后期高温胁迫对 “济南 17' 和 “鲁麦 21 ’ 的醇溶蛋白 (Gli. ) 含量 (A)、麦谷蛋白 (Glu.) 含量 (B)、 麦谷蛋白与醇溶蛋白含量之比 (Gli./Glu. index) (C) 和粒麦谷 蛋白大聚合体 (GMP) 含量 (D) 的影响

Fig.3 Gliadin (Gli.) content (A), glutenin (Glu.) content (B), Glu./Gli. Index (C) and Glutenin micropolymer (GMP) content (D) of 'Ji' nan17' and 'Lumai21' under heat stress T0, T1, T2, T3: 同图 1 See Fig. 1

\section{5 产量}

灌浆期高温引起小麦产量的降低(图 4C), 灌浆 前期的高温主要是由于穗粒数的显著降低引起的 (图 4A); 灌浆中期和后期的高温主要是子粒重降低 (图 4B)。两个品种的小麦所表现出来的趋势是一
致的。

\section{6 品质}

容重是国家收购小麦时重要的定级依据, 是子 粒大小、形状、整齐度、腹沟深浅、肧乳质地的综合反 映, 与出粉率显著正相关。高温胁迫后子粒容重降 低, 其中灌浆中期和后期高温胁迫对子粒容重的影 响更为明显 $(p<0.05)$ (表 2$)$ 。

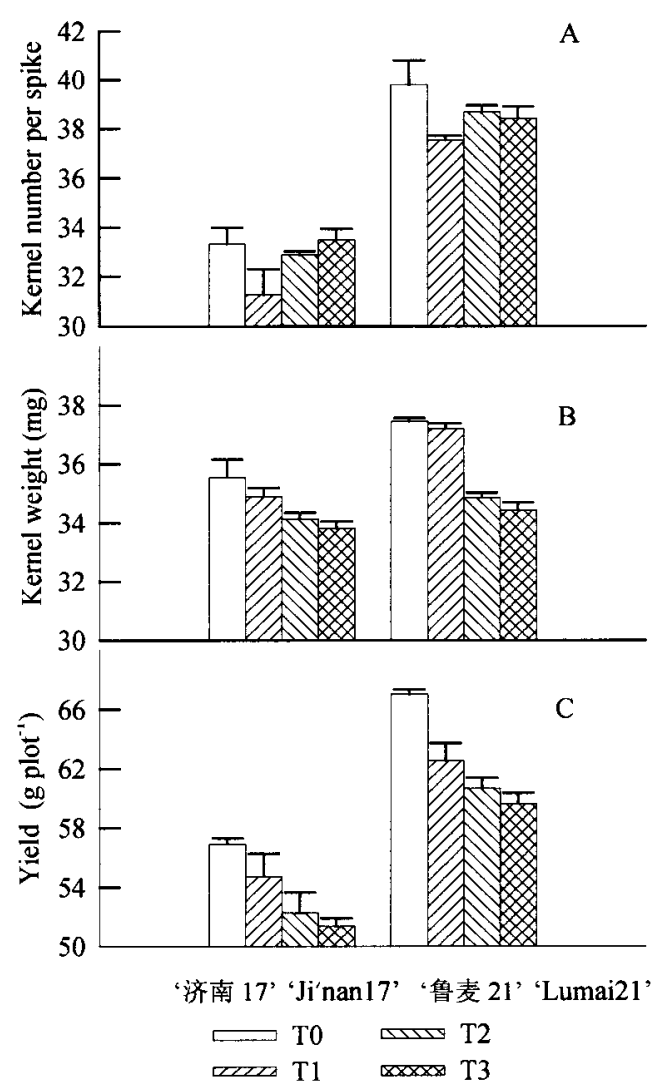

图 4 子粒灌浆前期、中期和后期高温胁迫对 “济南 17’ 和 “鲁麦 21” 的穗粒数 $(A)$ 、粒重 $(B)$ 和每盆产量 $(\mathrm{C})$ 的影响

Fig.4 Kernel number per spike (A), kernel weight (B) and yield (C) of 'Ji' nan17' (A) and 'Lumai21' (B) under heat stress $\mathrm{T} 0, \mathrm{~T} 1, \mathrm{~T} 2, \mathrm{~T} 3$ : 同图 1 See Fig. 1

膨胀势是指小麦面粉在达到糊化温度后的吸水 特性, 膨胀势高有利于加工优质的面条或水饺 (McCormick \& Panozzo, 1991)。利用快速粘度仪可以测 定面粉的高峰粘度, 它与淀粉品质和面条的加工品 质关系最为密切, 一般表现为高峰粘度高, 淀粉的品 质和面条的加工品质就好 (Bhattacharya, 1996)。灌 浆前期经历高温胁迫的小麦的膨胀势和高峰粘度显 著升高 $(p<0.05)$ 。灌浆中期和后期的高温胁迫则 造成膨胀势和高峰粘度显著降低。高温胁迫也导致 蛋白质和湿面筋含量升高, 其中灌浆前期和后期高 
温对子粒蛋白质和湿面筋含量的影响较为明显 $(p<0.05)$, 而灌浆中期高温胁迫的影响并不显著 (表 2)。

沉降值是单位重量的面粉或全麦粉在弱酸条件
下, 经水合作用, 形成絮状沉淀物的体积, 其数值高 时蛋白质品质表现较好。在灌浆前期高温处理的小 麦沉降值显著升高 $(p<0.05)$, 而灌浆中、后期高温 处理的沉降值显著降低 $(p<0.05)$ (表 2$)$ 。

表 2 灌浆期不同阶段分别处在不同温度下的 “济南 $\mathbf{1 7}$ ’ 和 ‘鲁麦 $\mathbf{2 1}$ ’的淀粉和蛋白质品质

Table 2 Starch and quality traits of 'Ji' nan17' and 'Lumai21' under different grain filling stage heat stress

\begin{tabular}{|c|c|c|c|c|c|c|c|}
\hline \multirow{2}{*}{$\begin{array}{c}\text { 品种 } \\
\text { Cultivar }\end{array}$} & \multirow{2}{*}{$\begin{array}{c}\text { 处理 } \\
\text { Treatments }\end{array}$} & \multirow{2}{*}{$\begin{array}{c}\text { 容重 } \\
\text { Test weight } \\
\left(\mathrm{g} \bullet \mathrm{L}^{-1}\right)\end{array}$} & \multicolumn{2}{|c|}{$\begin{array}{c}\text { 淀粉品质指标 } \\
\text { Starch quality parameters }\end{array}$} & \multicolumn{3}{|c|}{$\begin{array}{c}\text { 蛋白质品质指标 } \\
\text { Protein quality parameters }\end{array}$} \\
\hline & & & $\begin{array}{c}\text { 膨胀势 } \\
\text { Swelling power } \\
\left(\mathrm{g}^{\bullet} \mathrm{g}^{-1}\right)\end{array}$ & $\begin{array}{c}\text { 高峰粘度 } \\
\text { PeakVisc. } \\
\text { (RVU) }\end{array}$ & $\begin{array}{c}\text { 蛋白质含量 } \\
\text { Protein } \\
\text { contents }(\%)\end{array}$ & $\begin{array}{c}\text { 湿面筋含量 } \\
\text { Wet gluten } \\
\text { contents }(\%)\end{array}$ & $\begin{array}{c}\text { 沉降值 } \\
\text { Sedimentation } \\
\text { volume }(\mathrm{ml})\end{array}$ \\
\hline \multirow{4}{*}{$\begin{array}{l}\text { ‘济南 17’ } \\
\text { ‘Ji'nan 17’ }\end{array}$} & T0 & $778^{\mathrm{bA}}$ & $6.84^{\mathrm{bB}}$ & $202.00^{\mathrm{bB}}$ & $13.27^{\mathrm{cB}}$ & $41.34^{\mathrm{cC}}$ & $49.6^{\mathrm{bB}}$ \\
\hline & $\mathrm{T} 1$ & $783^{\mathrm{aA}}$ & $8.04^{\mathrm{aA}}$ & $209.33^{\mathrm{aA}}$ & $14.26^{\mathrm{bA}}$ & $43.42^{\mathrm{bB}}$ & $56.8^{\mathrm{aA}}$ \\
\hline & $\mathrm{T} 2$ & $769^{\mathrm{cB}}$ & $6.00^{\mathrm{cC}}$ & $196.92^{\mathrm{cB}}$ & $13.30^{\mathrm{cB}}$ & $41.43^{\mathrm{cC}}$ & $47.9^{\mathrm{cC}}$ \\
\hline & $\mathrm{T} 3$ & $768^{\mathrm{cB}}$ & $5.54^{\mathrm{dD}}$ & $195.22^{\mathrm{cB}}$ & $14.39^{\mathrm{aA}}$ & $46.83^{\mathrm{aA}}$ & $46.7^{\mathrm{dD}}$ \\
\hline \multirow{4}{*}{$\begin{array}{l}\text { ‘鲁麦 21’, } \\
\text { ‘Lumai 21’ }\end{array}$} & TO & $802^{\mathrm{aA}}$ & $8.84^{\mathrm{bB}}$ & $240.25^{\mathrm{bB}}$ & $11.56^{\mathrm{cB}}$ & $32.95^{\mathrm{bB}}$ & $34.9^{\mathrm{bB}}$ \\
\hline & $\mathrm{T} 1$ & $803^{\mathrm{aA}}$ & $9.64^{\mathrm{aA}}$ & $246.25^{\mathrm{aA}}$ & $12.66^{\mathrm{bA}}$ & $33.08^{\mathrm{bB}}$ & $39.5^{\mathrm{aA}}$ \\
\hline & $\mathrm{T} 2$ & $789^{\mathrm{bA}}$ & $8.00^{\mathrm{cC}}$ & $235.50^{\mathrm{cC}}$ & $11.58^{\mathrm{cB}}$ & $31.72^{\mathrm{cC}}$ & $33.4^{\mathrm{cC}}$ \\
\hline & $\mathrm{T} 3$ & $788^{\mathrm{bA}}$ & $7.94^{\mathrm{cC}}$ & $229.83^{\mathrm{dC}}$ & $13.01^{\mathrm{aA}}$ & $34.07^{\mathrm{aA}}$ & $33.0^{\mathrm{cC}}$ \\
\hline
\end{tabular}

处理之间, 标有相同大、小写字母处理的差异经 LSD 检验没有达到 $p<0.01$ 和 $p<0.05$ 的水平 Figures share the same capital or little letter has no least significant differences ( LSD) at $p<0.01$ and $p<0.05$ between the treatments

\section{3 讨 论}

小麦是我国主要的粮食作物, 随着小麦单产的 大幅度提高, 我国的小麦已经做到了丰年有余, 目前 小麦的加工品质及其与栽培环境之间的关系越来越 受到人们的重视。关于温度对不同品种小麦光合特 性和产量方面的影响, 国内有所报道( 许为钢等, 1999; 张嵩午，1999)。我国小麦品种的品质与世界 优质小麦的差距主要表现为加工品质的差距, 蛋白 质含量方面的差距相对较小 (秦武发和李宗智, 1989）。我国北方冬麦区在子粒灌浆后期气温较高, 对小麦产量和品质有不利的影响, 另外全球性的气 候变暖将会进一步加重这种不利影响 (Blumenthal et $a l,, 1990)$, 因此深入研究我国小麦品种与高温胁迫 的关系, 能为优质小麦的发展提供理论依据。

小麦子粒灌浆期常常遇到高温天气(日最高温 度超过 $30{ }^{\circ} \mathrm{C}$ ), 在我国的黄淮冬麦区常常表现为干 热风的危害,造成小麦粒重和产量的降低(金善宝, 1996）。高温条件下小麦子粒中淀粉积累速率加快， 但是积累时间缩短, 导致粒重降低; 而蛋白质的积累 过程受环境因素影响较小, 从而导致子粒中蛋白质 含量相对升高 (Jenner, 1991)。。Blumenthal 等(1993) 认为, 高温条件下较有利于醇溶蛋白的生物合成而 不利于麦谷蛋白的生物合成, 使醇溶蛋白和麦谷蛋
白的比例以及麦谷蛋白大聚合体的组成发生改变, 降低了小麦的加工品质。但对于小麦灌浆期不同阶 段的高温胁迫产量和品质方面的影响, 目前尚不清 楚。

本研究的控温试验把小麦子粒灌浆期分为 3 个 阶段进行研究, 即在子粒灌浆的前期、中期和后期分 别进行了高温胁迫处理。结果发现, 不同灌浆阶段 高温胁迫下小麦蛋白质积累量减少 (图 2A) 和氮素 收获指数降低(图 2B), 子粒中蛋白质积累速率在高 温期内加快, 但高值持续期缩短（图 $1 \mathrm{AB}$ )。子粒蛋 白质的组成对不同灌浆阶段高温的响应存在显著差 异, 前期高温导致麦谷蛋白/醇溶蛋白的比值增加 (图 3C)、GMP 含量升高(图 3C)、沉降值增加(表 2); 而灌浆中后期高温却导致上述三项指标显著降低。

根据前人的研究结果, 当日最高气温超过 $32{ }^{\circ} \mathrm{C}$ 后, 小麦产量降低、品质下降 (Stone \& Nicolas，1994; Blumenthal et al., 1991; Wrigley et al., 1994), 本研究 结果表明, 当小麦在子粒灌浆前期经历了 $10 \mathrm{~d} 35{ }^{\circ} \mathrm{C}$ 的高温胁迫后，小麦的穗粒数、粒重和产量显著降 低, 但标志品质优劣的膨胀势、高峰粘度、湿面筋含 量和沉降值升高;而灌浆中后期高温条件下上述指 标均显著降低。这表明小麦产量和品质的形成是一 个既相互联系又相互独立的过程。从本研究的结果 来分析, 子粒灌浆前期的高温对小麦产量影响没有 
后期明显 (图 4B、C), 但对提高淀粉品质却较为有利 (表 2); 灌浆中期高温不仅造成粒重和产量的显著 降低(图 4B、C), 而且还导致品质的降低 (表 2); 灌浆 后期高温在造成粒重减小、产量降低和品质下降的 同时, 却有利于蛋白质含量的提高 (表 2)。这表明 小麦淀粉的积累与品质的形成是两个既相互联系又 相互独立的过程, 高温条件下子粒蛋白质含量的升 高是淀粉积累量减少造成的。

\section{参 考 文 献}

Blumenthal CS, Barlow EWR, Wrigley CW (1990). Global warming and wheat. Nature, 347, 235.

Blumenthal CS, Barlow EWR, Wrigley CW (1993). Growth environment and wheat quality: the effects of heat stress on dough properties and gluten proteins. Journal of Cereal Science, 18, 2 -21 .

Blumenthal CS, Bekes F, Batey IL, Wringely CW, Moss HJ, Mares DJ, Barlow EWR (1991). Interpretation of grain quality results from wheat variety trials with reference to higher temperature stress. Australian Journal of Agricultural Research, 42, 325 -334 .

Graybosch RA, Peterson CJ (1995). Enviromental modification of hard winter wheat flour protein composition. Australian Journal of Plant Physiology, 22,45-51.

IPCC(1992). Climate Change: The Supplementary Report to the IPCC Scientific Assessment. Cambridge University Press, London.

Jenner CF (1991). The physiology of starch and protein deposition in the endosperm of wheat. Australian Journal of Plant Physiology, $18,211-226$.

Jin SB(金善宝) (1996). Chinese Wheat Science (中国小麦学). China Agriculture Press, Beijing. (in Chinese)

Keeling PL, Bacon PJ, Holt DC(1993). Elevation temperature reduces starch deposition in wheat endosperm by reducing the activity of soluble starch synthase. Planta, 191, $341-348$.

Li YG (李永庚), Jiang GM (蒋高明), Yang JC (杨景成) (2003). Effect of temperature on carbon and nitrogen metabolism, yield and quality of wheat. Acta Phytoecologica Sini$c a$ (植物生态学报), 27,164-169. (in Chinese with English abstract)

Liao JX(廖建雄), Wang GX(王根轩) (2000). The effects of increasing $\mathrm{CO}_{2}$, temperature and drought on the chemical composition of wheat leaves. Acta Phytoecologica Sinica (植物生态学 报), 24,744-747. (in Chinese with English abstract)
McCormick KM, Panozzo JF (1994) . A swelling power test for selecting potential noodle quality wheat. Australian Journal of Agricultural Research, 42, 317-323.

Qin WF(秦武发), Li ZZ (李宗智) (1989). Effects of ecological factors on wheat quality. Beijing Agricultural Science (北京农业 科学) , 4, 21-24. (in Chinese)

Randall PJ, Moss HJ (1990). Some effect of temperature regime during grain filling on wheat quality. Australian Journal of Agricultural Research, 41, 602-617.

Smith GP, Gooding MG(1996). Relationship of wheat quality and nitrogen application in regions of England. Annual of Applied Biology, 129, $97-102$.

Spiertz JHJ (1974). Grain growth and distribution of dry matter in the wheat plant as influenced by temperature, light energy and ear size. Netherlands Journal of Agricultural Science, 22,207220 .

Stone PJ, Nicolas ME(1994). Wheat cultivars vary widely in their response of grain yield and quality of short period of post anthesis heat stress. Australian Journal of Plant Physiology, 21, 887 900 .

Sun H(孙辉)，Yao DN(姚大年), Li BY (李保云), Liu GT(刘 广田), Zhang SZ(张树榛) (1998). Effects of genetic and environmental factors on the content of gluteninmacropolymer. Journal of Triticeae Crops (麦类作物学报)，20,23-27. (in Chinese)

Uhlen AK, Hafskjold R, Kalhovd AH, Sahlstrom S, Longva A, Magnus EM ( 1998 ). Effect of cultivar and temperature during grain filling on wheat protein content, composition, and dough mixing properties. Cereal Chemistry, 75, 460-465.

Wardlaw IF (1970). The early stage of grain development in wheat: Response to light and temperature in a single varity. Australian Journal of Biology Science, 23, $765-774$.

Wrigley CW, Blumenthal CS, Gras PW, Barlow EWR (1994). Temperature variation during grain filling and changes in wheatgrain quality. Australian Journal of Plant physiology, 21,875885 .

$\mathrm{Xu} \mathrm{WG}$ (许为钢), Hu L(胡琳), Gai JY (盖钧镒) (1999). A study on heat tolerance of wheat cultivars. Acta Agriculturae Boreali-Sinica (华北农学报), 14(2), 20-24. (in Chinese)

Zhang SW (张高午) (1999). Cold typical wheat and its biological characteristics. Acta Agronomica Sinica (作物学报), 25, 608 - 615. (in Chinese with English abstract)

Zhu JB (朱金宝), Liu GT(刘广田), Liu SZ(刘树榛) (1995)。 Influence of genotype and environment on wheat bake quality. Acta Agronomica Sinica (作物学报), 21, 679-684. (in Chinese with English abstract)

责任编委: 李风民 责任编辑: 张丽赫 